\title{
SIGILLATA HISPANICA DEL CERRO DE LOS INFANTES (GRANADA)
}

\author{
ENCARNACION SERRANO RAMOS
}

El material que vamos a dar a conocer procede de prospecciones realizadas por Don Francisco Peregrin (1) en el Cerro de los Infantes (Pinos Puente, Granada), lugar en el que se viene ubicando la ciudad de Ilurco (2).

De este mismo yacimiento hemos estudiado anteriormente un buen lote de cerámicas vidriadas (3) y de sigillata hispánica fabricada esta última en los hornos romanos de Cartuja (Granada) (4), materiales que como el que hoy es objeto de nuestra atención, se encuentran en la colección del señor Peregrin, autor, a su vez, de un trabajo inédito sobre marcas de sigillata (itálica, gálica e hispánica) en su mayoría procedente del citado lugar (5).

En este trabajo nos vamos a centrar en la sigillata hispánica producida en el centro de Andújar (6) con el deseo de poder contribuir a un mejor conocimiento de la dispersión que tuvo tal núcleo alfarero (7).

\section{ESTUDIO DEL MATERIAL.}

1.- Fragmento de pared de la forma Drag. 37. De la decoración se conserva parte de una metopa con tres motivos verticales alineados de líneas onduladas que terminan en hoja triangular por la parte superior. (Roca $n .^{\circ} 421$ ). El motivo vertical de separación formado por dobles líneas onduladas con guirnalda bifoliácea (Fig. 1,1). El mismo motivo en un molde de Roca, Lám. 5, 47 y 48. En Sotomayor, Lám. 55, 420, tenemos el mismo esquema pero el remate de las líneas onduladas es distinto.

(1) A quién agradecemos el habernos proporcionado este material para su estudio. Así mismo queremos hacer extensible el agradecimiento al Dr. Don J. E. Ferrer Palma por la ayuda que nos presto para fotografiar parte del material.

(2) GOMEZ MORENO, M., Miscelaneas. Historia-Arte-Arqueologia. Primera serie. La Antiguedad. Madrid 1949, pp, 371-373, donde dice: 'Pinos Puente......, es sucesor de otra ciudad antiquísima, rival acaso de Iliberri en el señorio de la comarca, Municipio romano también y cuyos vestigios subsisten sobre un cerro que llaman de los Infantes a dos kilómetros en dirección hacia Córdoba'. Siguen ésta opinión SCHULTEN. A., Ilurco en R.E. de PaulyWissowa. IX, p. 1093 y TOVAR, A., Iberische Landeskunde. Die Wolker und die Stadte des antiken Hispanien, I Baetica, Baden-Baden, 1974, pp. 136-137. (3) SERRANO RAMOS, E., 'Cerámica romana vidriada del Cerro de los Infantes (Granada)'. Actas del XV. Cong. Nac. Arq. Lugo 1977, Zaragoza 1979, pp. 1.019-1.026. IDEM., 'Hallazgos de cerámica romana vidriada en la Bética', Baetica, $n .{ }^{\circ} 2$, 1979, pp. 147-158.

(4) SERRANO RAMOS, E., Sigillata hispánica de los hornos de Cartuja (Granada). Studia Archaeologica n. ${ }^{\circ} 57$. Valladolid $1979 .^{2}$ fig. 4 , 24; fig. 7 , 40, 41; fig. 12, 65, 66, 67,68, 69, 70; Lám. II, 7; Lám. IV y Lám. V.

(5) PEREGRIN, F. Marcas de sigillata (inédito).

(6) SOTOMAYOR, M., 'Andújar centro de produccion y exportación de sigillata a Mauritania'. Not. Arq. Hisp. I Madrid 1972, pp. 263-289. IDEM. 'Centro de producción de sigillata de Andújar', Actas del XII. Cong. Nac. Arq. Jaén, 1971, Zaragoza, 1973, pp. 689-698. ROCA ROUMENS, M. Sigillata hispánica producida en Andújar (Jaén), Instituto de Estudios Giennenses, Jaén, 1976. SOTOMAYOR, M., PEREZ CASAS, A. y ROCA ROUMENS, M., 'Los alfares romanos de Andújar (Jaén), 1973'. Not. Arq. Hisp. IV, Madrid, 1976, pp. 111-147. SOTOMAYOR, M., Marcas y estilos en la sigillata decorada de Andújar. Instituto de Estudios Giennenses, Jaén 1977. SOTOMAYOR, M., ROCA, M., y SOTOMAYOR, N., 'Los alfares romanos de Andújar. Campanas de 1974, 1975 y 1977', Not. Arq. Hisp. VI, Madrid, 1979, pp. 443-497. SOTOMAYOR, M., "Fabricantes y estilos de sigillata decorada en Andújar (Jaén)". Actas del XV Cong. Nac. Arq. Lugo 1977, Zaragoza 1979, pp. 1.047-1.056.

Los trabajos citados en el texto como Roca y Sotomayor corresponden a los publicados por estos autores en 1976 y 1977 respectivamente. (7) En las descripciones de los colores de las pastas y barnices hemos seguido las tablas de STEIGER, R., Tafel zur Farbbezeichnung römischer Keramik. Basel, 1971. Y al igual que hace M. Sotomayor empleamos las letras a y b para indicar el color oscuro o el claro. En las descripciones de los motivos decorativos hemos seguido los términos empleados por Roca y Sotomayor con el fin de evitar confusión y para mayor homogeneización. 
Pasta de color tierra de Siena tostada (11b), con algunas vacuolas y partículas amarillentas arcilloso-calcáreas; de fractura no muy regular. El barniz rojo inglés claro (18a) algo anaranjado, brillante y algo caedizo en el exterior.

2.- Fragmento de pared posiblemente de la forma Drag. 37 y con la misma decoración que el anterior; como remate de las líneas onduladas verticales hojas triangulares más pequeñas que las superiores (Fig. 1,2).

La pasta y el barniz igual que el anterior.

3.- Fragmento de pared posiblemente de la forma Drag. 37. La decoración distribuida en una sóla zona a tenor de la anchura de ésta: Como motivo de separación de metopas guirnalda bifoliácea entre dobles líneas onduladas (Roca $\left.n .^{\circ} 100\right)$ y en el interior líneas onduladas paralelas rematadas por una palmeta en la parte superior (Roca 520), y en la inferior una peana. (Fig. 1,3). Aunque esta composición la recogen tanto Roca (Lám. 5,47, 49 y 50; Lám. 28, 142), como Sotomayor (Lám. 55, 420), no con el mismo tipo de palmeta, ni peana.

Pasta ocre carne (6 b), con partículas amarillentas arcilloso-calcáreas, de fractura no muy regular. El barniz rojo inglés claro (18a), brillante y algo perdido en la parte de la decoración que más sobresale.

4.- Pequeño fragmento posiblemente de la forma Drag. 37. Conserva de la decoración unas líneas onduladas paralelas que están rematadas por la parte inferior por unas peanas; son los mismos motivos que los del fragmento anterior y posiblemente también estuvieron rematados por una palmeta. La decoración queda delimitada por la zona inferior por dos pequeños baquetones (Fig. 1,4).

Pasta ocre de Roma (9b), con vacuolas y partículas amarillentas arcilloso-calcáreas. Barniz rojo inglés claro (18a), casi mate y muy mal conservado.

5.- Fragmento de borde de la forma Drag. 37. La decoración distribuída en metopas y como motivo de separación guirnalda bifoliácea entre dobles líneas onduladas (Sotomayor, Lám. $18,141)$, a la izquierda el final de una rama ondulada rematada por una pequeña palmera y en la de la derecha posiblemente la misma palmeta circular. (Fig. 1, 5).

Pasta ocre de Roma (9b), con partículas amarillentas arcilloso-calcáreas y abundantes vacuolas; fractura irregular. Barniz tierra de Pozzuoli (17a), algo deteriorado en el exterior.

6. - Fragmento de borde de la forma Drag. 37. Sólo conserva de la decoración el motivo de separación de metopa que consiste en una guirnalda bifoliácea entre triples líneas onduladas (Roca n. ${ }^{\circ}$ 97?) (Fig. 1, 6).

Pasta tierra de Siena tostada (11b) con partículas amarillentas arcilloso-calcáreas y vacuolas; fractura casi regular. El barniz rojo inglés claro (18a), brillante y de una gran calidad.

7.- Fragmento de borde y pared posiblemente de la forma Drag. 37 con decoración de ruedecilla en el exterior. Esta decoración es una característica del centro de Andújar (Roca, Lám 31 y 32), como lo es también del de Granada (Serrano, fig. 7 y Lám. II) (Fig. 1, 7). 
Pasta ocre de Roma (9b), con partículas amarillentas arcilloso-calcáreas y algunas vacuolas; fractura regular. El barniz rojo inglés claro (18a), de muy buena calidad.

8.- Fragmento de borde y pared de la forma Drag. 37, con un diámetro de boca de 17,5 cms. La decoración está dividida en dos zonas separadas por dos baquetones. En la superior metopas con doble círculo concéntrico con roseta en el interior. El motivo de separación es una línea vertical ondulada. En la inferior la repetición del motivo de la superior. (Fig. 1, 8). La misma composición es un molde recogido por Roca (Lám. 16, 222).

La pasta de color tierra de Siena tostada (11b), con partículas amarillentas arcillosocalcáreas y abundantes vacuolas de diversos tamaños; fractura bastante recta. Barniz rojo inglés claro (18a), algo más brillante en la superficie interna, homogéneo y adherente.

9.- Fragmento de pared de la zona inferior, posiblemente de la forma Drag. 37. La decoración pertenece a una metopa con un círculo de línea sogueada encerrando roseta. El motivo de separación está formado por una línea vertical ondulada. (Fig. 1,9).

Pasta tierra de Siena tostada (11b), con partículas amarillentas arcilloso-calcáreas; fractura irregular. Barniz rojo inglés claro (18a), brillante y homogéneo.

10. - Fragmento de borde de la forma Drag. 37. Conserva la decoración de la banda superior a base de círculos de línea sogueada con roseta tetrapétala en el interior (Roca n. ${ }^{\circ}$ 281) (Fig. 1, 10). El mismo motivo lo tenemos en un molde recogido por Roca, Lám. 9, 95 y 103; Lám. 12, 157 y el mismo tipo de borde y decoración en Sotomayor, Lám. 25, 206.

Pasta tierra de Siena tostada (11b), con partículas amarillentas arcilloso-calcáreas; fractura irregular. Barniz rojo inglés claro (18a), casi mate.

11.- Fragmento de borde de la forma Drag. 37. Conserva parte de la decoración de la banda superior con círculo de línea sogueada con roseta en el interior, motivo éste que se va intercalando entre los círculos arriba y abajo (Roca $n .^{\circ}$ 578). (Fig. 1, 11). Motivos circulares con roseta tetrapétala y pequeñas rosetas recoge Roca en un molde en la Lám. 11, 128, la composición es similar a la nuestra aunque con pequeñas diferencias. En Sotomayor, Lám. 25, 213,tenemos unos círculos sogueados con 'botón en el centro' que muy bien pudiera tratarse de nuestro motivo.

Pasta ocre carne (6b), con pequeñas vacuolas y partículas amarillentas arcilloso-calcáreas; fractura regular. El barniz rojo inglés claro (18a), mate en el interior.

12.- Fragmento de borde de la forma Drag. 37. Se conserva parte de la decoración de la zona superior formada por cículos enlazados de línea ondulada con posible palmeta circular en el interior (Fig. 2, 12). El motivo puede corresponder al n. ${ }^{\circ} 318$ de Roca aunque sin el círculo de línea cortada del exterior. Círculo de línea ondulada con palmeta en el interior aparecen recogidos por Sotomayor, aunque no con la misma disposición que los nuestros (Sotomayor, Lám. 31, 266, 271).

Pasta ocre carne (6b), con abundantes partículas amarillentas arcilloso-calcáreas; fractura irregular. Barniz rojo inglés claro (18a), brillante y perdido en algunas partes. 
13. - Fragmento de borde de la forma Drag. 37. En la zona superior círculos de línea continua con roseta. (Fig. 2, 13). El mismo tipo de decoración en un molde recogido por Roca,Lám. $4,32$.

Pasta tierra de Siena tostada (11b), con partículas amarillentas arcilloso-calcáreas; fractura irregular. El barniz rojo inglés claro (18a), poco brillante.

14. - Fragmento de pared de la zona inferior; entre líneas verticales de separación un círculo de línea ondulada con roseta de cinco pétalos en el interior (Roca n. ${ }^{\circ}$ 552) (Fig. 2, 14).

Pasta ocre de Roma (9b), con partículas amarillentas arcilloso-calcáreas; fractura irregular. El barniz tierra de Pozzuoli (17a), mate y algo perdido.

15. - Fragmento de pared; como motivo de separación de las zonas una girnalda bifoliácea entre dos pequeños baquetones (Roca $n .^{\circ} 47$ ) y en la inferior doble círculo concéntrico de línea interrumpida el externo y continua el interno con una roseta (posiblemente corresponda al $\mathrm{n}^{\circ}{ }^{\circ}$ 577 de Roca) (Fig. 2, 15).

Pasta ocre de Roma (9b), con partículas amarillentas arcilloso-calcáreas; fractura no muy regular. El barniz tierra de Pozzuoli (17a), algo brillante y perdido en algunas partes.

16. - Fragmento de pared de la forma Drag. 37. Bajo el borde una línea de pequeños círculitos (Roca . $^{\circ}$ 37) y bajo ellos círculos con roseta en el interior. La decoración muy mal impresa (Fig. 2, 16).

Pasta tierra de Siena tostada (11b), con partículas amarillentas arcilloso-calcáreas; fractura irregular. El barniz tierra de Pozzuoli (17a), no muy brillante y algo perdido.

17. - Pequeño fragmento decorado con círculo que contienen roseta en el interior (las rosetas corresponden al n. 569 de Roca). Estos círculos al disponer de un espacio muy pequeño no están completos por la parte superior y como motivo de separación dos pequeños baquetones (Fig. 2, 17).

Pasta tierra de Siena tostada (11b), con partículas amarillentas arcilloso-calcáreas; fractura irregular. El barniz tierra de Pozzuoli (17a), más brillante en el interior que en el exterior.

18. - Fragmento de pared con parte de la decoración de la zona inferior. En éste círculo sogueado con roseta tetrapétala en el interior (Roca $n .{ }^{\circ} 281$, motivo que tenemos también en Granada, Serrano n. ${ }^{\circ} 48$ y Lám. V, 46 y 55) y a su vez dentro de un gran círculo. Entre estos motivos circulares se van intercalando dos círculos sogueados con roseta. La decoración esta mal conseguida. (Fig. 2, 18).

Pasta ocre de Roma (9b), con abundantes partículas amarillentas arcilloso-calcáreas y algunas vacuolas; fractura irregular. Barniz tierra de Pozzuoli (17a), algo perdido sobre los motivos decorativos y poco brillante.

19. - Fragmento de la forma Drag. 37. Como motivo de separación dos pequeños baquetones y en el interior una decoración de elementos angulares enlazados (posiblemente corresponda al n. 35 de Roca, motivo que tenemos también en Granada, Serrano n. ${ }^{\circ}$ 96). En la superior 
círculo sogueado con roseta tetrapétala en el interior (Roca $n .{ }^{\circ} 281$ ) y en la inferior el mismo motivo y la repetición posible de éste dentro de un gran círculo. Decoración muy defectuosa (Fig. 2, 19).

Pasta ocre carne (6b), con abundantes partículas amarillentas arcilloso-calcáreas; fractura regular. El barniz tierra de Pozzuoli (17a), algo brillante.

20.- Fragmento de pared con parte de la decoración de la zona inferior. Dentro de un círculo sogueado roseta de seis pétalos en el interior (Roca $n .{ }^{\circ}$ 604) y a la derecha tres líneas verticales onduladas de separación de metopa. Como motivo de separación de zonas dos pequeños baquetones (Fig. 2, 20).

Pasta tierra de Siena tostada (11b), con partículas amarillentas arcilloso-calcáreas; fractura irregular. El barniz rojo inglés claro (18a), poco brillante.

21.- Fragmento con parte de la decoración de la zona inferior, separada de la superior por dos pequeños baquetones. En ésta dentro de un círculo sogueado una roseta de múltiples pétalos y como motivo de separación una línea vertical (Roca $n .^{\circ}$ 166) y a ambos lados dos motivos bifoliáceos, que deben repetirse en la parte baja, como podemos ver en el siguiente fragmento y en un molde recogido por Roca, Lám. 10, 118. (Fig. 2, 21).

Pasta Van Dyke morena (24b) por defecto de cocción; fractura irregular. El barniz tierra de Pozzuoli (17a), poco brillante en el exterior.

22.- Fragmento con parte de la decoración de la zona inferior que queda delimitada por un pequeño baquetón. En ésta la decoración es muy similar al fragmento anterior: círculos puntiformes con rosetas de múltiples pétalos en el interior, separados por línea vertical y guirnalda bifoliácea tocando el baquetón (Fig. 2, 22).

Pasta ocre de Roma (9b), con partículas amarillentas arcilloso-calcáreas; fractura casi regualr. El barniz rojo inglés claro (18a), de buena calidad pero algo perdido en las zonas donde la decoración presenta más relieve.

23. - Fragmento posiblemente de la forma Drag. 37, con la decoración distribuída en dos zonas separadas por dos pequeños baquetones. En la superior parte de un círculo y en la inferior una copa (Roca $n .^{\circ}$ 622) y a la derecha una roseta de ocho pétalos dentro de un círculo (Roca n. ${ }^{\circ}$ 598). Tema que recogen tanto Roca (Lám. 27, 110 y Lám. 30, 190) como Sotomayor (Lám. 54, 407) pero con distinto número de pétalos (Fig. 2, 23).

Pasta tierra de Siena tostada (11b), con partículas amarillentas arcilloso-calcáreas; fractura casi regular. Barniz rojo inglés claro (18a), bastante descascarillado.

24. - Fragmento de pared posiblemente de la forma Drag. 29/37. La decoración distribuída en dos zonas por medio de una guirnalda bifoliácea entre dos baquetones; de la superior sólo se conserva parte de un motivo vegetal. En la inferior dobles círculos concéntricos de línea cortada con adormidera en el interior, entre los que se intercalan un motivo vertical que está coronado por un elemento trifoliáceo. La misma decoración la recoge Roca, Lám. 24, 33, (Fig. 2, 24).

Pasta ocre carne (6b), con abundantes partículas amarillentas arcilloso-calcáreas; fractura irregular. Barniz tierra de Pozzuoli (17a), brillante y algo perdido en el exterior. 
25. - Fragmento de pie y pared de la forma Drag. 37. De la decoración queda parte de dobles círculos concéntricos de la zona inferior y bajo ellos entre dos pequeños baquetones un friso de dobles círculos concéntricos de línea cortada el externo y continua el interno (Roca $n .^{\circ}$ 230). El mismo tipo de friso en Roca, Lám. 9, 115, (Fig. 2, 25).

Pasta tierra de Siena tostada (11b), con partículas amarillentas arcillos-calcáreas; fractura irregular. El barniz tierra de Pozzuoli (17a), poco brillante.

26. - Pequeño fragmento decorado con dos círculos enlazados de línea contínua con hoja lanceolada en el interior. Aunque el motivo de círculo y hoja lo recoge Roca $n .^{\circ} 330$, el de ella es de línea cortada y no continua como el nuestro (Fig. 2, 26).

Pasta de color tierra de Siena tostada (11b), con partículas amarillentas arcilloso-calcáreas; fractura irregular. El barniz tierra de Pozzuoli (17a) no muy bien conservado y algo mate.

27. - Fragmento de pared de la forma Drag. 37? Conserva parte de la decoración de la zona inferior que queda separada de la superior por dos pequeños baquetones y en ésta dobles círculos de línea ondulada el exterior y continua el de dentro con botón central, alternando con guirnalda bifoliácea y pequeños círculos en los ángulos. (Fig. 2, 27). Un esquema muy similar recoge Roca en la Lám. 22,2 aunque la alternancia se hace con círculo de línea continua con motivo vegetal en el interior. Círculos iguales no tenemos en Roca.

Pasta ocre carne (6b), con algunas partículas amarillentas arcilloso-calcáreas; fractura irregular. Barniz rojo inglés claro (18a), brillante en el exterior y casi mate en el interior, muy deteriorado.

28. - Fragmento de pared probablemente de la forma Drag. 37, con la decoración separada por un pequeño baquetón. En la superior círculo de línea interrumpida con uno liso en el interior y en la inferior la repetición de unos círculos de línea ondulada con uno continuo y botón central. El círculo superior similar al $n .^{\circ} 251$ de Roca aunque el nuestro es de tamaño menor (Fig. 2, 28).

La pasta igual que el fragmento anterior y en cuanto al barniz, rojo inglés claro (18a), brillante y en buen estado de conservación, salvo en la parte que más sobresale la decoración.

29. - Fragmento de pared de la forma Drag. 37, con la decoración dividida en dos zonas por un pequeño baquetón. En la superior unos círculos de línea ondulada con uno pequeño en el centro (Roca $n .^{\circ} 265$ aunque el nuestro es algo mayor) y en la inferior el inicio de un círculo sogueado. (Fig. 2, 29).

La pasta y el barniz igual que el anterior.

30-31. - Fragmento de pared de la forma Drag. 37. Como en los ejemplares anteriores un pequeño baquetón es el motivo de separación de las zonas; en la superior círculo de línea interrumpida con uno liso en el interior a la derecha el posible inicio de una palmeta (Roca n. $^{\circ}$ 415) y en la inferior la repetición de círculos de línea ondulada que encierran a uno liso y botón central. (Fig. 2, 30). Este mismo motivo lo tenemos también en la zona inferior en el siguiente fragmento (Fig. 2, 31). 
La pasta en ambos tierras de Siena tostada (11b), con partículas amarillentas arcillosocalcáreas; fractura irregular. Barniz rojo inglés claro (18a), brillante y algo perdido en ambas caras.

32. - Fragmento de borde de la forma Drag. 37. En la banda superior un círculo de línea interrumpida con otro liso en el interior (Roca $n .{ }^{\circ} 251$ ) y a la derecha una palmeta (Roca $n .{ }^{\circ} 415$ ). Un pequeño baquetón sirve de motivo de separación con la inferior de la que no se conserva nada. (Fig. 3, 32).

Pasta y barniz igual que el anterior.

33. - Fragmento de pared de la forma Drag. 37. Un pequeño baquetón es el motivo de separación de las zonas, en la superior se aprecia el final de un círculo de línea ondulada y en la inferior círculo sogueado con uno pequeño de línea continua en el centro. (Fig. 3, 33).

Pasta ocre carne (6b), con partículas amarillentas arcilloso-calcáreas; fractura totalmente irregular. El barniz rojo inglés claro (18a), poco brillante y algo perdido.

34. - Fragmento de pared con dobles círculos concéntricos, el externo sogueado, de línea ondulada el interno y con uno pequeño y liso en el interior. No tenemos en Roca este mismo motivo. (Fig. 3, 34).

Pasta ocre carne (6b), con partículas amarillentas arcilloso-calcáreas; fractura irregular. Barniz rojo inglés claro (18a) algo anaranjado, brillante; ha saltado en algunos puntos del interior y en el exterior en donde la decoración sobresale más.

35. - Fragmento de pared de la forma Drag. 37. Los círculos son idénticos a los del fragmento anterior, pero entre éstos se intercala un motivo vegetal estilizado (Roca $n .^{\circ} 478$, Serrano . $^{\circ}$ 69 de Granada) y bajo éste un pequeño anillo. (Fig. 3, 35).

Pasta tierra de Siena tostada (11b), con partículas amarillentas arcilloso-calcáreas y algunas vacuolas; de fractura irregular. El barniz rojo inglés claro (18a), brillante y algo perdido en las zonas de más relieve.

36. - Fragmento de pared de la forma Drag. 37? La división entre las zonas se realiza por un pequeño baquetón, en la inferior que es la única que se conserva la repetición de dobles círculos concéntricos, de línea ondulada el externo y contínua el interno (Roca $n .^{\circ} 265$ aunque el nuestro es algo mayor). La misma composición la recoge Roca Lám. 22, 1. (Fig. 3, 36).

Pasta tierra de Siena tostada (11b), con partículas amarillentas arcilloso-calcáreas; fractura irregular. Barniz rojo inglés claro (18a), mate.

37.- Fragmento con parte de la decoración de la zona superior, con un doble círculo concéntrico sogueado el externo y de línea interrumpida el interno y a la izquierda tres líneas onduladas (Fig. 3, 37).

Pasta tierra de Siena tostada (11b), con partículas amarillentas arcilloso-calcáreas; fractura irregular. El barniz tierra de Pozzuoli (17b), no muy brillante. 
38. - Fragmento de borde y pared de la forma Drag. 37. La decoración está dividida en dos zonas por un baquetón, en la superior alternan círculos concéntricos sogueado el externo y de línea interrumpida el interno (Roca $n .^{\circ} 385$ sin el motivo del interior) con otros más pequeños que pueden corresponder al 257 de Roca y en la inferior un motivo de estilización vegetal (Roca n..$^{\circ} 478$ que tenemos también en Granada, Serrano n. ${ }^{\circ}$ 69) (Fig. 3, 38).

La pasta de color tierra de Siena tostada (11b), con partículas amarillentas arcillosocalcáreas; fractura regular. El barniz rojo inglés claro (18a), brillante.

39.- Fragmento de pared con una decoración de triples círculos concéntricos: liso, sogueado y liso. Creemos que corresponden al que recoge Roca en la Lám. 24, 32. Similares pero sin el del interior en Sotomayor, Lám. 23, 188-189 y 191 (Fig. 3, 39).

Pasta ocre de Roma (9b), con partículas amarillentas arcilloso-calcáreas; fractura irregular. El barniz tierra de Pozzuoli (18a), brillante en el exterior y mate en el interior.

40.- Fragmento de pared de la forma Drag. 29 ó 29/37. Conserva parte de la decoración de la zona inferior a base de círculos concéntricos entre los que se intercalan un motivo cruciforme con palmetas circulares en los extremos (Roca n. ${ }^{\circ} 483$ ) (Fig. 3, 40).

Pasta tierra de Siena tostada (11b), con partículas amarillentas arcilloso-calcáreas y algunas vacuolas; fractura regular. El barniz rojo inglés claro (18a), brillante y de una gran calidad.

41.- Fragmento de la forma Drag. 29?, con parte de la decoración de la zona superior. En el interior de una metopa enmarcada por líneas verticales onduladas, círculo de línea interrumpida (Roca $n .^{\circ} 208$ ) y en las esquinas pequeño círculo de línea continua (Roca $n .{ }^{\circ} 199$ ). El mismo esquema lo recoge Sotomayor, Lám. 54, 409, con la única diferencia que en el nuestro aparece el círculo continuo en el interior del de línea interrumpida (Fig. 3, 41).

Pasta tierra de Siena tostada (11b), con partículas amarillentas arcilloso-calcáreas; fractura irregular. Barniz ocre claro tostado (14b), mate y algo perdido en la decoración.

42.- Pequeño fragmento con doble círculo concéntrico y un motivo vegetal (Roca 496?). (Fig. 3, 42).

Pasta ocre de Roma (9b), con abundantes partículas amarillentas arcilloso-calcáreas y algunas vacuolas; fractura regular. El barniz tierra de Pozzuoli (18a), brillante y algo perdido en las zonas de más relieve.

43. - Fragmento de borde y pared de la forma Drag. 37, con un diámetro de $14 \mathrm{cms}$. La decoración aparece distribuída en dos zonas, separadas por dos pequeños baquetones; en la superior que es la única que se conserva la repetición de dobles círculos concéntricos, de línea ondulada el externo y sogueado el interno (Roca $n .^{\circ}$ 228). (Fig. 3, 43).

Pasta tierra de Siena tostada (11b), con pequeñas vacuolas y partículas amarillentas arcilloso-calcáreas; fractura irregular. Barniz rojo inglés claro (18a), brillante y homogéneo.

44.- Fragmento de borde de la forma Drag. 37. Conserva la decoración de la banda superior con dobles círculos concéntricos, de línea ondulada el externo y sogueado el interno (Roca 
n. ${ }^{\circ} 228$ ). La separación de las bandas se realiza mediante un friso de guirnalda bifoliácea (Fig. 3 , 44).

Pasta ocre carne (6b), con partículas amarillentas arcilloso-calcáreas; fractura casi regular. Barniz rojo inglés claro (18a), brillante y deteriorado en las zonas con decoración.

45. - Pequeño fragmento de la zona inferior con el mismo motivo circular que los anteriores y a la derecha parte de un círculo pequeño bajo el cual y dentro de una cartela la marca M.S. [m] que había sido recogida por Don Francisco Peregrin (8) (Fig. 3, 45).

Pasta tierra de Siena tostada (11b), con partículas amarillentas arcilloso-calcáreas; fractura algo irregular. Barniz tierra de Pozzuoli (17a), muy bien conservado.

46. - Fragmento de pared con una decoración de metopas. En el interior de un doble círculo concéntrico un grifo (Roca $n .^{\circ} 740$ ) y a la izquierda tres líneas verticales onduladas entre dos guirnaldas bifoliáceas, motivos que se repiten enmarcando la decoración por la parte superior. (Fig. 3, 46).

Pasta ocre de Roma (9b), con algunas partículas amarillentas arcilloso-calcáreas y numerosas vacuolas; fractura irregular. El barniz totalmente perdido.

47.- Probable fragmento de la forma Drag. 37. Conserva el motivo de separación de bandas con una guirnalda bifoliácea entre dos baquetones (Roca $\left.n .{ }^{\circ} 51\right)$ y parte de la decoración de la zona inferior con un círculo sogueado que encierra una ave con la cabeza vuelta hacia atrás (Roca n..$^{\circ}$ 367, sin el círculo del exterior) y a la derecha una hoja lanceolada (Roca $n .^{\circ} 441$; Serrano Fig. 18 n. ${ }^{\circ} 64$ procedente de Granada) (Fig. 3, 47).

Pasta ocre de Roma (9b), con pequeñas vacuolas y partículas amarillentas arcilloso-calcáreas; fractura irregular. Barniz rojo inglés claro (18a), brillante y algo más deteriorado en las partes más salientes de la decoración.

48. - Fragmento decorado con un doble círculo concéntrico sogueado el externo y de línea interrumpida el interno con una ave pequeña en el interior (Roca n. ${ }^{\circ}$ 719). (Fig. 3, 48).

Pasta ocre de Roma (9b), con partículas amarillentas arcilloso-calcáreas; fractura regular. El barniz tierra de Pozzuoli (17a), casi mate y perdido en las partes de más relieve.

49. - Fragmento perteneciente a la zona inferior; dentro de un círculo de línea continua una ave. Aunque Roca recoge punzones similares no hemos localizado ninguno como éste (Roca Lám. 47, 48 y 58). (Fig. 3, 39).

Pasta tierra de Siena tostada (11b), con partículas amarillentas arcilloso-calcáreas; fractura no muy regular. El barniz rojo inglés claro (18a), brillante y bien conservado.

50. - Pequeño fragmento probablemente de la forma Drag. 37. Dentro de un círculo de línea ondulada un conejo agazapado (Sotomayor, Lám. 43, 351-352, pero dentro de festones) (Fig. 4, 50). 
Pasta tierra de Siena tostada (11b), con partículas amarillentas arcilloso-calcáreas y algunas vacuolas; fractura regular. Barniz tierra de Pozzuoli (17a), brillante.

51.- Pequeño fragmento posiblemente de la forma Drag. 37. En la única metopa que se conserva un perro corriente hacia la izquierda (Roca $n .^{\circ} 639$, pero sin la línea ondulada); como motivo de separación una línea ondulada y por la parte superior una guirnalda bifoliácea. Posiblemente pertenezca a un vaso que presenta la zona superior muy ancha y la inferior muy estrecha como si fuera una cenefa y en ésta en el interior de cada metopa un animal (Sotomayor, Lám. 42, n. ${ }^{\circ} 342,343$ ). (Fig. 4,51).

Pasta tierra de Siena tostada (11b), con partículas amarillentas arcilloso-calcáreas; fractura regular. Barniz rojo inglés claro (18a), no muy bien conservado y poco brillante.

52.- Pequeño fragmento de la parte inferior de un vaso, con la decoración de una metopa, posiblemente comprendida entre líneas onduladas, con un conejo en el interior (Roca $n .^{\circ} 661$ ?). (Fig. 4, 52).

Pasta ocre de Roma (9b), con partículas amarillentas arcilloso calcáreas y vacuolas; fractura irregular. El barniz tierra de Pozzuoli (17a), mate.

53. - Fragmento de pared posiblemente de la forma Drag. 37. Como motivo de separación de metopas tres líneas verticales onduladas y en el interior un jabali (Roca $n .^{\circ}$ 702) y delante una hoja larga y estilizada (Roca n. ${ }^{\circ}$ 507). En el fragmento recogido por Roca en la Lám. 24, 20, tenemos la misma distribución que el nuestro pero el motivo es un grifo en lugar de un jabalí (Fig. $4,53)$.

Pasta tierra de Siena tostada (11b), con vacuolas y partículas amarillentas arcilloso-calcáreas; fractura regular. Barniz rojo inglés claro (18a), brillante y bien conservado.

54. - Fragmento de borde de la forma Drag. 37, con parte de la decoración de la zona superior y como motivo de separación de metopas nueve líneas onduladas y en su interior una ave (Roca n. ${ }^{\circ}$ 722). (Fig. 4, 54).

Pasta ocre carne (6b), con vacuolas y partículas amarillentas arcilloso-calcáreas; fractura irregular. Barniz rojo inglés claro (18a), brillante y algo deteriorado en el exterior.

55.- Pequeño fragmento con parte de un motivo cruciforme, en el punto de unión de dos líneas onduladas una palmeta (Roca $n .^{\circ} 415$ ) y sobre ella dos pequeñas aves. Aunque el tema lo tenemos recogido en Sotomayor, Lám. 38, 319, 321, 323-325; Lám. 39, 326-330, en ninguno de ellos aparecen las aves directamente sobre la palmeta, sí otros animales; Lám. 34, 292 (Fig. 4, 55).

La pasta ocre de Roma (9b), con partículas amarillentas arcilloso-calcáreas; fractura irregular. Barniz tierra de Pozzuoli (17a), brillante y algo descascarillado.

56. - Fragmento de pared probablemente de la forma Drag. 37. El motivo de separación de zona lo forman dos baquetones con guirnalda bifoliácea, queda sólo parte de la decoración inferior formada por una palmeta (Roca $n .^{\circ} 415$ ) y a la izquierda ave con la cabeza vuelta (Roca $n .^{\circ}$ 737) sobre una hoja y detrás parte de una línea ondulada. El tema del ave sobre hoja lo recoge 
Roca en la Lám. 26, 93, aunque el ave es distinta a la nuestra. El mismo esquema en Sotomayor, Lám. 38, 325, con la diferencia de que aparece sobre una línea ondulada. Los motivos de palmeta y a ve en el autor citado, Lám. 38, 325, Lám. 39, 330 y Lám. 51, 384. (Fig. 4, 56).

Pasta ocre carne (6b), con vacuolas y partículas amarillentas arcilloso-calcáreas; fractura regular. Barniz rojo inglés claro (18a), algo brillante y muy deteriorado.

57.- Fragmento de pared de la forma Drag. 37 ? Por la parte superior ciñe la decoración una guirnalda bifoliácea y bajo ella una ave (Roca $n .^{\circ} 737$ ), toda la decoración con muy poco relieve. (Fig. 4, 57).

Pasta ocre de Roma (9b), con partículas amarillentas arcilloso-calcáreas; fractura irregular. $\mathrm{El}$ barniz rojo inglés claro (18a), poco brillante.

58.- Pequeño fragmento decorado con una pequeña ave sobre línea ondulada (Roca $n .^{\circ}$ 734). (Fig. 4, 58).

Pasta tierra de Siena tostada (11b), con partículas amarillentas arcilloso-calcáreas y algunas vacuolas; fractura irregular. El barniz tierra de Pozzuoli (17a), brillante y algo deteriorado.

59.- Fragmento de borde de la forma Drag. 37. Conserva parte de la decoración de la zona superior, línea ondulada con pequeña palmeta hacia abajo (Roca $n .^{\circ} 508$ ) y pequeño arbusto hacia arriba (Roca $n .^{\circ} 538$ ), motivos que deben repetirse alternativamente. La misma composición en Andújar (Sotomayor, Lám. 13, 90, con los mismos motivos pero ambos en la misma posición y 93-95 igual que el nuestro pero la decoración corresponde a la zona inferior y Lám. 14, 101) (Fig. 4, 59).

Pasta tierra de Siena tostada (11b), con partículas amarillentas arcilloso-calcáreas; fractura muy irregular. Barniz rojo inglés claro (18a), brillante.

60.- Pequeño fragmento con parte de una metopa y como motivo central una roseta de ocho pétalos (Roca n. ${ }^{\circ} 598$ ) entre líneas onduladas. Sotomayor recoge éste mismo motivo alternando con palmetas pero sólo con una línea ondulada (Lám. 34, 295). (Fig. 4, 60).

Pasta ocre carne (6b), con partículas amarillentas aricilloso-calcáreas; fractura regular. Barniz tierra de Pozzuoli (17a), muy bien conservado y poco brillante.

61. - Fragmento de borde de la forma Drag. 37, con un diámetro de $14 \mathrm{cms}$. La decoración distribuída en dos zonas, en la superior metopas separadas por guirnaldas bifoliáceas y en el interior roseta de siete pétalos (Roca $n .^{\circ}$ 562); el motivo de separación de las zonas son unas perlas entre baquetones (Roca n. ${ }^{\circ}$ 60). En Sotomayor (Lám. 1, 4 con la firma de M.S.M. y Lám. 50, 380) tenemos la misma composición (Fig. 4, 61).

Pasta ocre carne (6b), con pequeñas partículas amarillentas arcilloso-calcáreas; fractura irregular. Barniz rojo inglés claro (18a), más brillante en el interior que en el exterior y algo deteriorado en ésta última parte.

62.-- Fragmento de borde de la forma Drag. 37. La decoración dividida en metopas y como motivo de separación cuatro líneas onduladas con un motivo bifoliáceo en la parte superior que 
se va repitiendo, y en el interior de las metopas palmeta (Roca $n .^{\circ} 433$ ) y adormidera (Roca $n .^{\circ}$ 481). (Fig. 4, 62).

Pasta tierra de Siena tostada (11b), con partículas amarillentas arcilloso calcáreas y vacuolas; fractura regular. El barniz rojo inglés claro (18a), brillante y algo perdido donde el relieve es más acusado, probablemente de la forma Drag. 37. Un pequeño friso con guirnalda bifoliácea comprendido entre dos baquetones es el motivo de separación de las dos zonas (Roca n. ${ }^{\circ}$ 51). Se conserva parte del motivo de la inferior, compuesto por una doble arquería con la línea externa ondulada y la interna cortada y a la derecha una guirnalda bifoliácea coronada por una hoja (Roca n. ${ }^{\circ}$ 503). La misma arquería la recoge Sotomayor, Lám. 16, 126. (Fig. 4, 63).

Pasta ocre de Roma (9b), con partículas amarillentas arcilloso-calcáreas, y fractura irregular. Barniz tierra de Pozzuoli (17a), no muy brillante y perdido en las zonas de más relieve.

64. - Fragmento de pared con parte de la decoración de una metopa. Como motivo de separación triple líneas onduladas entre guirnaldas bifoliáceas (Roca $n .^{\circ} 110$ ) y en el interior roseta de ocho pétalos (con seis pétalos en Roca, Lám. 3, 9; Lám. 28, 148; Lám. 29, 212 y Lám. 30, 214 y Sotomayor, Lám. 7, 49 y 50) y guirnalda bifoliácea en la parte superior e inferior. Como motivo de separación de zonas dos pequeños baquetones y bajo ellos una guirnalda. (Fig. 4, 64).

Pasta tierra de Siena tostada (11b), con partículas amarillentas arcilloso-calcáreas; fractura regular. El barniz rojo inglés claro (18a), brillante y de gran calidad.

65.- Pequeño fragmento decorado con una larga hoja estilizada e inclinada hacia dentro (Roca n. ${ }^{\circ}$ 448). (Fig. 4, 65).

Pasta tierra de Siena tostada (11b), con partículas amarillentas arcilloso-calcáreas y algunas vacuolas; fractura regular. El barniz rojo inglés claro (18a), brillante y de una gran calidad.

66. - Fragmento de borde y pared posiblemente de la forma Drag. 29, con dos estrías paralelas en la pared interna. De la decoración queda un motivo vegetal entre dos líneas onduladas rematadas por aves (Roca n. ${ }^{\circ}$ 719). (Fig. 4, 66).

Pasta tierra de Siena tostada (11b), con partículas amarillentas arcilloso-calcáreas y algunas vacuolas; fractura irregular. El barniz tierra de Pozzuoli (17a), brillante.

67. - Fragmento de pared decorado con una palmeta semicircular sobre doble vastago (igual en Sotomayor, Lám. 3, 12; Lám. 4, 20; Lám. 9, 66; Lám. 11, 73; Lám. 15, 115; Lám. 17, 136; Lám. 21, 179; Lám. 28, 239; Lám. 32, 277 y Lám. 41, 338) (Fig. 4, 67).

Pasta ocre de Roma (9b), con partículas amarillentas arcilloso-calcáreas; fractura irregular. El barniz tierra de Pozzuoli (17a), mate.

68. - Fragmento de pared de la forma Drag. 37. La decoración queda comprendida entre pequeños baquetones. En la superior una hoja alargada (Roca $n .^{\circ} 420$ ) y en la inferior una roseta (Roca $n .^{\circ}$ 605) y unos motivos circulares dispuestos en línea. (Fig. 4, 68).

Pasta tierra de Siena tostada (11b), con partículas amarillentas arcilloso-calcáreas y pequeñas vacuolas; fractura irregular. El barniz tierra de Pozzuoli (17a), brillante y en mal estado de conservación. 
69. - Fragmento de borde y pared posiblemente de la forma Drag. 29. El motivo de separación en la zona superior consiste en una guirnalda bifoliácea entre triples líneas onduladas y en el interior de la metopa un palmete (motivos similares en Roca $n .^{\circ} 432-436$ aunque éste presenta ciertas diferencias a los recogidos por la autora); en la inferior tres líneas onduladas de separación y en el centro un motivo circular. (Fig. 4, 69).

Pasta tierra de Siena tostada (11b), con partículas amarillentas arcilloso-calcáreas y algunas vacuolas; fractura casi regular. El barniz rojo inglés claro (18a), casi mate y algo perdido.

70.- Fragmento posiblemente de la forma Drag. 37 con parte de la decoración de la zona superior. En ésta unos motivos vegetales muy mal impresos. (Fig. 5, 70).

Pasta ocre de Roma (9b), con partículas amarillentas arcilloso-calcáreas y algunas vacuolas; fractura regular. El barniz tierra de Pozzuoli (17a), con más brillo en el interior que en el exterior.

71. - Fragmento de pared de la forma Drag. 37. La decoración está distribuída en dos zonas. En la superior alternan hojas lanceoladas (Roca $n .^{\circ} 441$ ) con motivos cruciformes (Roca n. ${ }^{\circ}$ 189). Como elemento de separación dos pequeños baquetones y en la inferior círculos de línea interrumpida (Roca $n .^{\circ} 212$ ) y bajo ellos un motivo vegetal. La decoración mal impresa. (Fig. 5, 71).

Pasta ocre de Roma (9b) con abundantes partículas amarillentas arcilloso-calcáreas y vacuolas; fractura irregular. El barniz tierra de Pozzuoli (17a), algo brillante y mal conservado.

72.- Fragmento de pared de la forma Drag. 37 ? con unas acanaladuras muy pronunciadas bajo el borde. De la decoración sólo se ha conservado, una línea ondulada de separación de metopas, un arco doble de línea ondulada al externo y de línea interrumpida el interno con posible grifo en el interior (motivo recogido por Roca $n .^{\circ} 738-747$ ) y una ova (Roca $n .^{\circ} 777$ ). (Fig. 5,72 )

Pasta tierra de Siena tostada (11b), con partículas amarillentas arcilloso-calcáreas; fractura casi regular. El barniz rojo inglés claro (18a), brillante y de buena calidad.

73. - Fragmento de pared probablemente de un vaso igual que el anterior y con una decoración similar. Bajo el borde una ova (Roca $n .^{\circ} 777$ ), tres líneas onduladas de separación de metopa (Roca n. ${ }^{\circ}$ 137) y un arco doble con grifo en el interior. (Fig. 5, 73).

Con el mismo tipo de pasta barniz que el anterior.

74. - Fragmento de borde y pared de la forma Drag. 37, con parte de una metopa. Como motivo de separación conserva dos líneas verticales onduladas; una guirnalda bifoliácea aparece enmarcando la decoración por la parte superior y por los lados y en el centro un doble círculo concéntrico de línea continua con algo en el interior. (Fig. 5, 74).

Pasta tierra de Siena tostada (11b), con partículas amarillentas arcilloso-calcáreas; fractura regular. El barniz rojo inglés claro (18a), brillante y bien conservado.

75. - Fragmento de la forma Drag. 37 con el borde de almendra. Una decoración de ruedecilla aparece bajo el borde y bajo ésta una línea de ovas (Roca $n .^{\circ} 21$ ), del resto solo queda parte 
de un círculo. Tiene el interés éste fragmento de ser el único que presenta las ovas bajo el borde de almendra (Roca p. 65) que por otra parte es lo frecuente en ésta forma (9) (Fig. 5, 75).

Pasta tierra de Siena tostada (11b), con partículas amarillentas arcilloso-calcáreas; fractura irregular. El barniz rojo inglés claro (18a), brillante y bastante bien conservado.

76. - Fragmento probablemente de la forma Drag. 37. Quedan restos de los motivos decorativos de la zona inferior: peana de una copa (Roca $n .^{\circ}$ 622) motivos vegetales, iguales a los recogidos por Roca en la Lám. 29, 210, y un friso entre dos baquetones con motivos en 's' (Roca n. ${ }^{\circ}$ 52) completa la decoración. (Fig. 5. 76).

Pasta ocre de Roma (9b), con partículas amarillentas arcilloso-calcáreas y algunas vacuolas; fractura irregular. El barniz tierra de Pozzuoli (17a), brillante pero muy perdido en el exterior.

77. - Fragmento de pared posiblemente de la forma Drag. 29/37, con la decoración dividida en dos zonas por dos pequeños baquetones. En la superior tenemos cuatro círculitos pequeños (Roca $n .^{\circ}$ 129) y los cuartos traseros de un animal, y en la inferior dobles círculos concéntricos de línea interrumpida el externo y contínua el interno que en cierran a un grifo (Roca $n .^{\circ} 742$ ), entre los círculos, dos líneas onduladas coronadas por dobles círculos concéntricos de línea continua (Roca n. ${ }^{\circ}$ 219. El mismo motivo con una sola línea ondulada en Roca Lám. 29, 198 y Sctomayor Lám. 36, 311 y Lám. 51, 389). (Fig. 5, 77).

Pasta ocre de Roma (9b), con partículas amarillentas arcilloso-calcáreas y algunas vacuolas; fractura regular. El barniz tierra de Pozzuoli (17a), brillante.

78. - Pequeño fragmento de la forma Drag. 29/37. Como motivo de separación dos pequeños baquetones. De la zona superior practicamente no se conserva nada y en el inferior una guirnalda bifoliácea entre dobles líneas onduladas (Roca $n .^{\circ} 102$ ) y en el interior de la metopa un motivo vegetal (Sotomayor, Lám. 44, 355). (Fig. 5, 78).

Pasta tierra de Siena tostada (11a), con partículas amarillentas arcilloso-calcáreas; fractura irregular. El barniz rojo inglés claro (18a), brillante.

79. - Pequeño fragmento posiblemente de la forma Drag. 37. Bajo el borde y a modo de friso la alternancia de ovas perforadas con dobles círculos concéntricos de línea continua (Roca $n .^{\circ}$ 219). La misma composición recoge Sotomayor, Lám. 8, 56, con la firma de M.S.M. (Fig. 5,79).

Pasta ocre de Roma (9b), con partículas amarillentas arcilloso-calcáreas; fractura irregular. El barniz tierra de Pozzuoli (17a), brillante y perdido en las zonas de más relieve.

80.- Fragmento de pared de la forma Drag. 37? Ciñe la decoración por la parte superior un friso de pequeños círculos entre baquetones (posiblemente correspondan al $n .^{\circ} 65$ de Roca). El resto está distribuído en metopas, una guirnalda bifoliácea entre dobles líneas onduladas (Roca n. ${ }^{\circ}$ 83) es el motivo de separación, y en el interior doble círculo concéntrico de línea continua (Roca.$^{\circ}$ 219) y a la derecha un gran círculo de línea interrumpida con algo en el interior. (Fig. $5,80)$. 
Pasta tierra de Siena tostada (11b), con partículas amarillentas arcilloso-calcáreas; fractura regular. El barniz rojo inglés claro (18a), sin brillo.

81. - Fragmento de pared con parte de un motivo vertical de separación de metopas, formado por dobles círculos concéntricos entre dobles líneas onduladas (Roca n. ${ }^{\circ}$ 123). (Fig. 5, 81).

Pasta tierra de Siena tostada (11b), con partículas amarillentas arcilloso-calcáreas; fractura irregular. El barniz rojo inglés claro (18a), poco brillante y perdido en las zonas de más relieves.

82. - Fragmento de pared de la zona inferior del vaso. Como motivo de separación de metopa círculos concéntricos entre líneas onduladas (Roca $\left.n .^{\circ} 124\right)$ y en el interior de la metopa los mismos motivos circulares (Fig. 5, 82).

La pasta y el barniz igual que en el anterior.

83. - Fragmento de borde de la forma Drag. 37. A manera de friso y enmarcando la decoración por la parte superior dobles círculos concéntricos de línea simple (Roca n. ${ }^{\circ}$ 219). (Fig. 5 , 83).

Pasta ocre carne (6b), con vacuolas y partículas amarillentas arcilloso-calcáreas; fractura irregular. El barniz rojo inglés claro (18a), brillante y bastante deteriorado en el exterior.

84. - Pequeño fragmento con parte de un círculo y a la dereca dos anillos lisos. Motivos muy frecuentes en Andújar (Sotomayor, Lám. 54, 409). (Fig. 5, 84).

Pasta ocre de Roma (9b), con abundantes partículas amarillentas arcilloso-calcáreas y vacuolas; fractura irregular. El barniz rojo inglés claro (18a), brillante en el interior y mate en el exterior.

85. - Pequeño fragmento con cinco líneas onduladas verticales de separación de metopas (Roca $n .^{\circ} 138$ ) y un anillo circular sobre el baquetón inferior. (Fig. 5, 85).

Pasta ocre carne (6b), con vacuolas y partículas amarillentas arcilloso-calcáreas; fractura regular. Barniz tierra de Pozzuoli (17a), brillante en el interior y mate en el exterior.

86. - Fragmento de pie y pared posiblemente de la forma Drag. 27. En el fondo y en el interior de una cartela con los extremos redondeados de $4 \mathrm{~mm}$. de ancho la siguiente marca: OPT[f]. Esta marcha había sido recogida por Don Francisco Peregrin, (10). En Andújar aparece precedida de EX (Roca n. ${ }^{\circ}$ 57, 58, 59; IIXOPT en Tarragona) (11). También la tenemos documentada en Lixus, Volubilis, Banasa y Tamuda bajo la fórmula EX OF PT (12).

En el fondo exterior presenta un grafito. (Fig. 5, 86).

Pasta tierra de Siena tostada (11b), con partículas amerillentas arcilloso-calcáreas; fractura muy irregular. El barniz rojo inglés claro (18a), algo brillante y muy mal conservado.

(10) PEREGRIN, F., Op. cit., p. 32 n. ${ }^{\circ} 116$.

(11) CIL, II, 4970, 181 .

(12) BOUBE, J. La Terra Sigillata Hispanique en Mauretanie Tingitane. Rabat, 1965, pp. 357-366. 


\section{CONCLUSIONES}

A la vista del material estudiado nos encontramos en primer lugar con una ausencia total de formas lisas, si exceptuamos un fragmento con la marca OPTF en el interior (Fig. 5, 86). Esta ausencia creemos que puede interpretarse no por una falta real, sino por lo atrayente que son las formas decoradas respecto a las otras formas. Hecho que hemos podido también comprobar al estudiar la sigillata hispánica fabricada en Cartuja (Granada) y aparecida en el Cerro de los Infantes.

En cuanto a las formas decoradas hay un predominio casi absoluto de la Drag. 37 frente a la 29 y 29/37, que aunque están representadas, aparecen en una mínima proporción.

Con respecto a las marcas hemos podido estudiar, además de la mencionada, un fragmento que lleva entre la decoración la de M.S.M. y sabemos de la existencia de otra por las notas inéditas sobre marcas de sigillata de Don Francisco Peregrin. Pero además tenemos una serie de piezas que sin llevar esta firma podemos considerar dentro de la producción de éste alfarero, tales como el de la Fig. 4, 59, donde la decoración presenta ramas onduladas que unen alternativamente palmeta y pequeño arbusto. (Sotomayor pp. 25-29). El de la Fig. 1, 5, con parte de las ramas onduladas con la pequeña palmeta hacia abajo dentro de una metopa y como motivo de separación, guirnalda bifoliácea entre dobles líneas onduladas (Sotomayor pp. 29-30). El de la Fig. 4, 61, donde tenemos un motivo vegetal-roseta-en el interior de una metopa y como elemento de separación una simple guirnalda bifoliácea; el mismo tema lo recoge Sotomayor, Lám. 1, 4, con la firma antes mencionada. También contamos con la presencia de ovas en los ángulos superiores de una metopa, Fig. 5, 72-73, y ovas perforadas alternando con pequeños círculos dobles, Fig. 5, 79. Tema este último que recoge Sotomayor (Lám. 8, 56) con la firma de M.S.M.

En la Fig. 5, 83, hemos presentado un borde decorado con pequeños círculos dobles que utilizan tanto M.S.M. como QVARTIO (Sotomayor, fig. 9). Nos inclinamos a favor de éste último por la falta de moldura que lo separa del resto de la decoración y por el tipo de borde, que es igual al recogido por Sotomayor en la Lám. 51, 382.

A TITI OPPI OF podemos atribuir el fragmento de la Fig. 3, 41, por la similitud con el recogido por Sotomayor (Lám. 54, 409). Y tal vez como apunta el citado autor (Sotomayor, p. 43) algún día puedan atribuirse a CVNDAS los de la Fig. 1, 1-2.

Tenemos representados además los típicos punzones de este centro productor, tales como el doble círculo concéntrico; la roseta circular; la pequeña palmeta; la palmeta circular; la palmeta; la hoja lanceolada; adormidera; ave; grifo; el perro y el conejo (Sotomayor fig. 9, 1-4, 6-9, 12-14), pero al existir un intercambio de punzones nos es imposible precisar más.

Como se puede observar existe un gran predominio de los productos de M.S.M., nada novedoso para nosotros, teniendo en cuenta de que se trata hasta ahora del alfarero mejor conocido. 

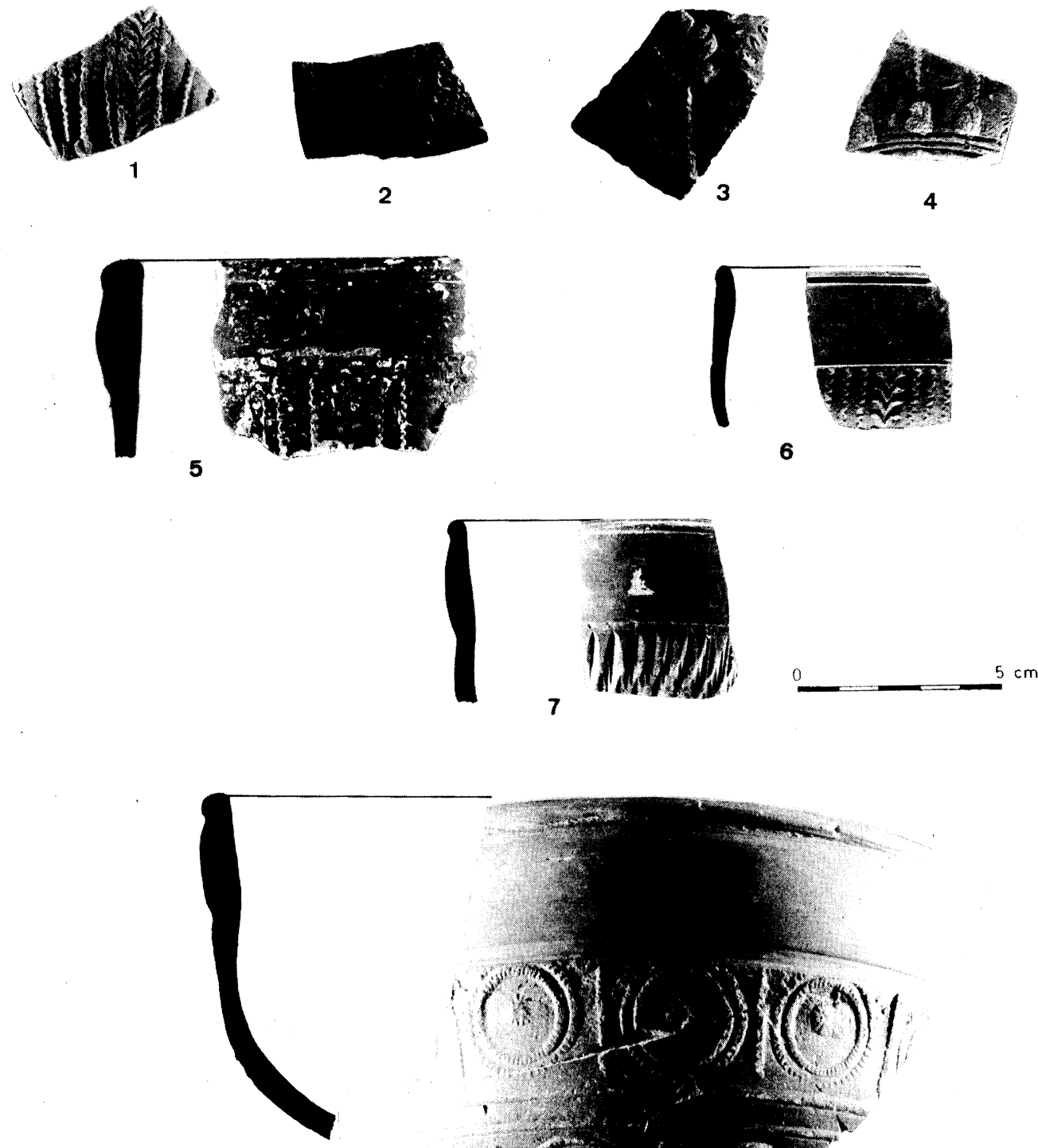

8
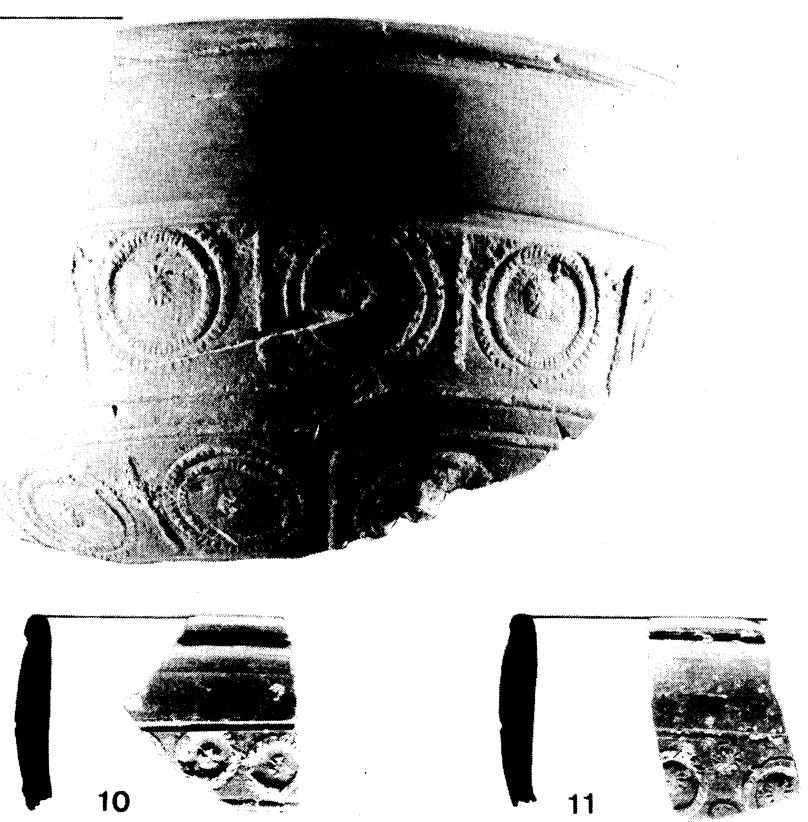


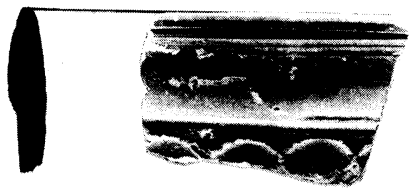

12

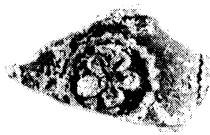

14

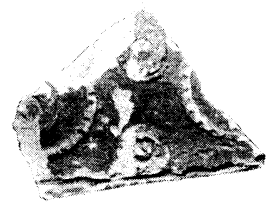

18
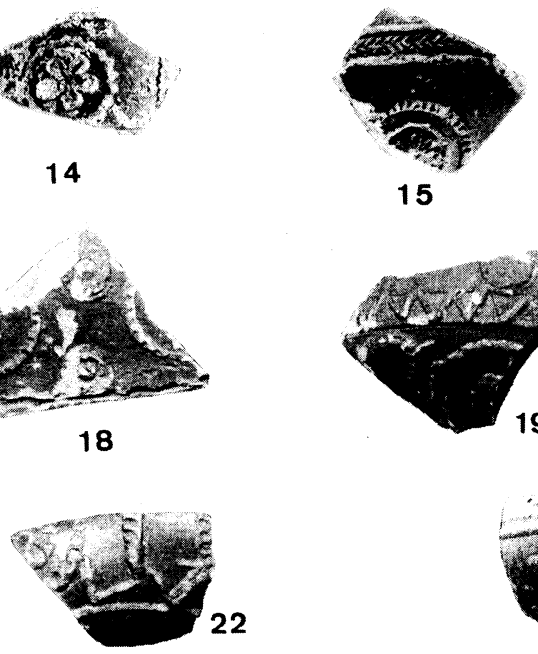

15
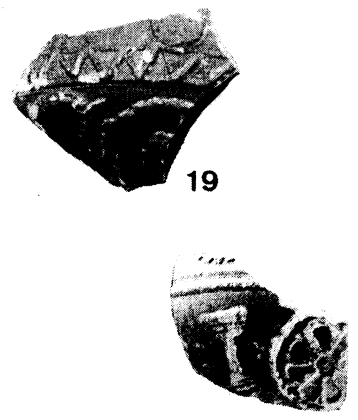

23
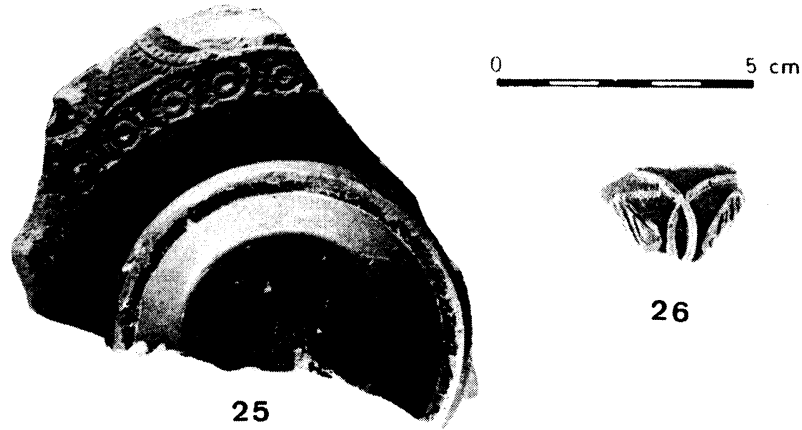

26

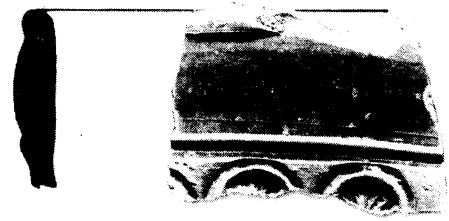

13
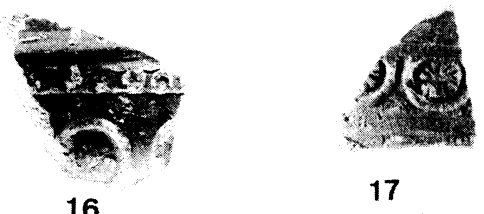

17
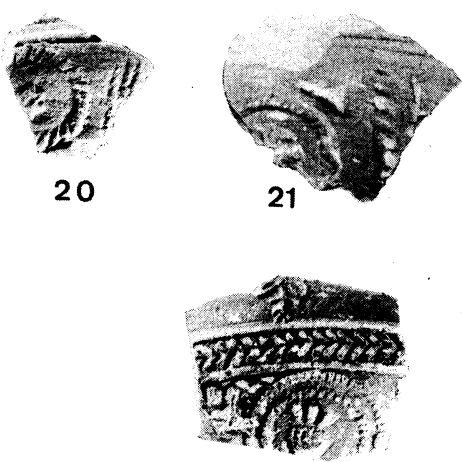

24
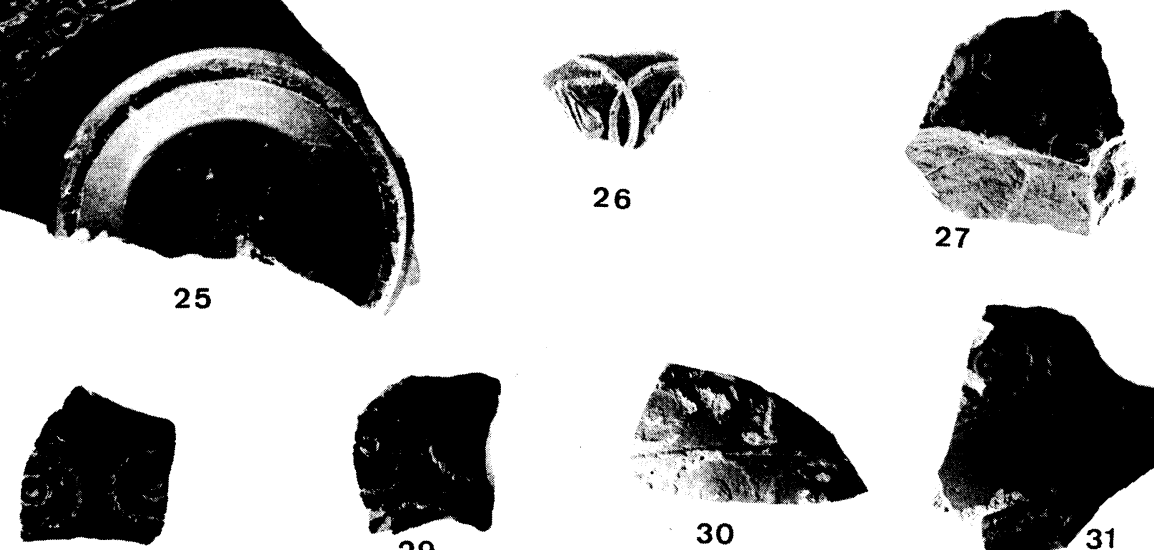

28
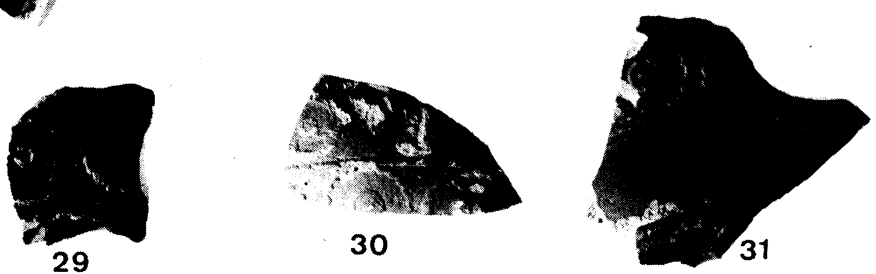


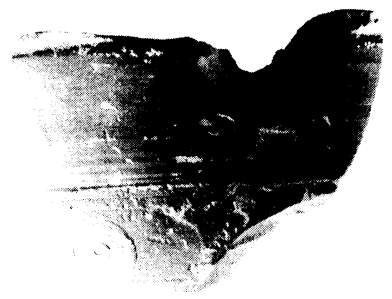

32

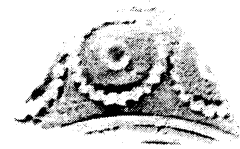

36

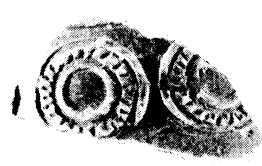

39
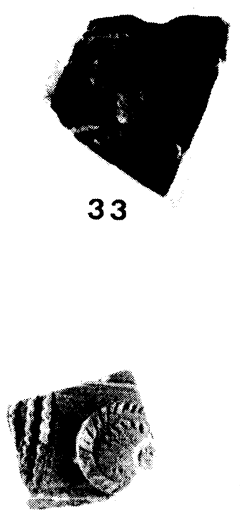

37

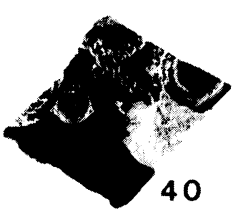

$\checkmark$

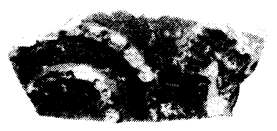

42

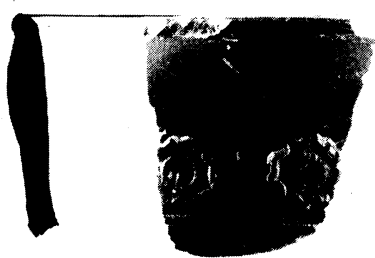

43

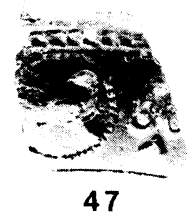

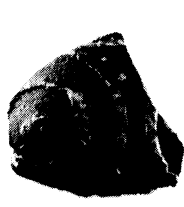

34
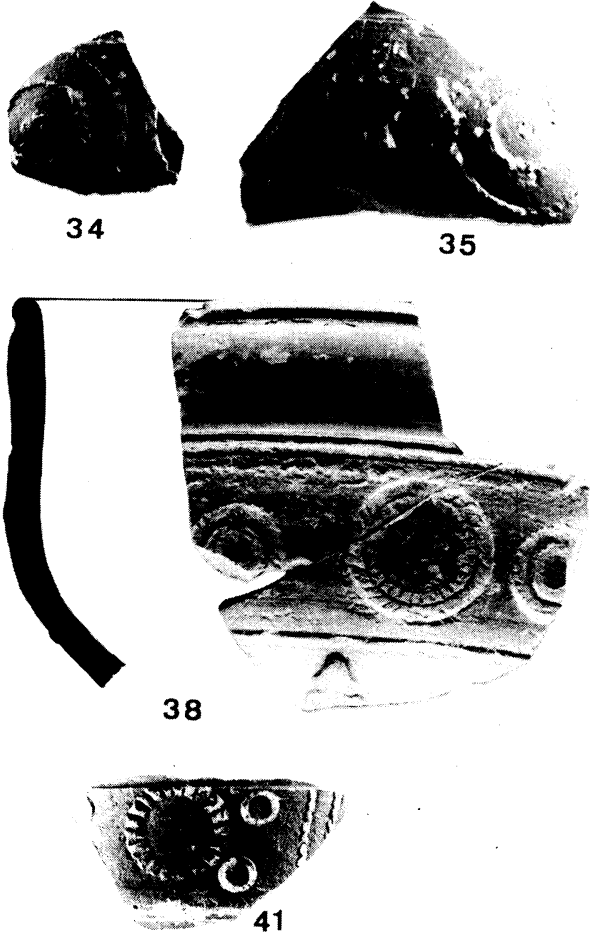

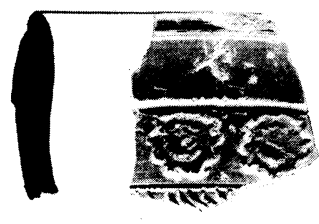

44

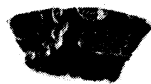

45
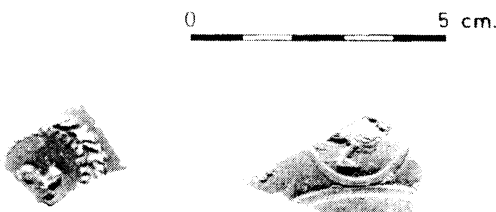

48

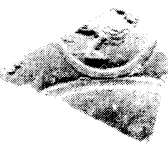

49 

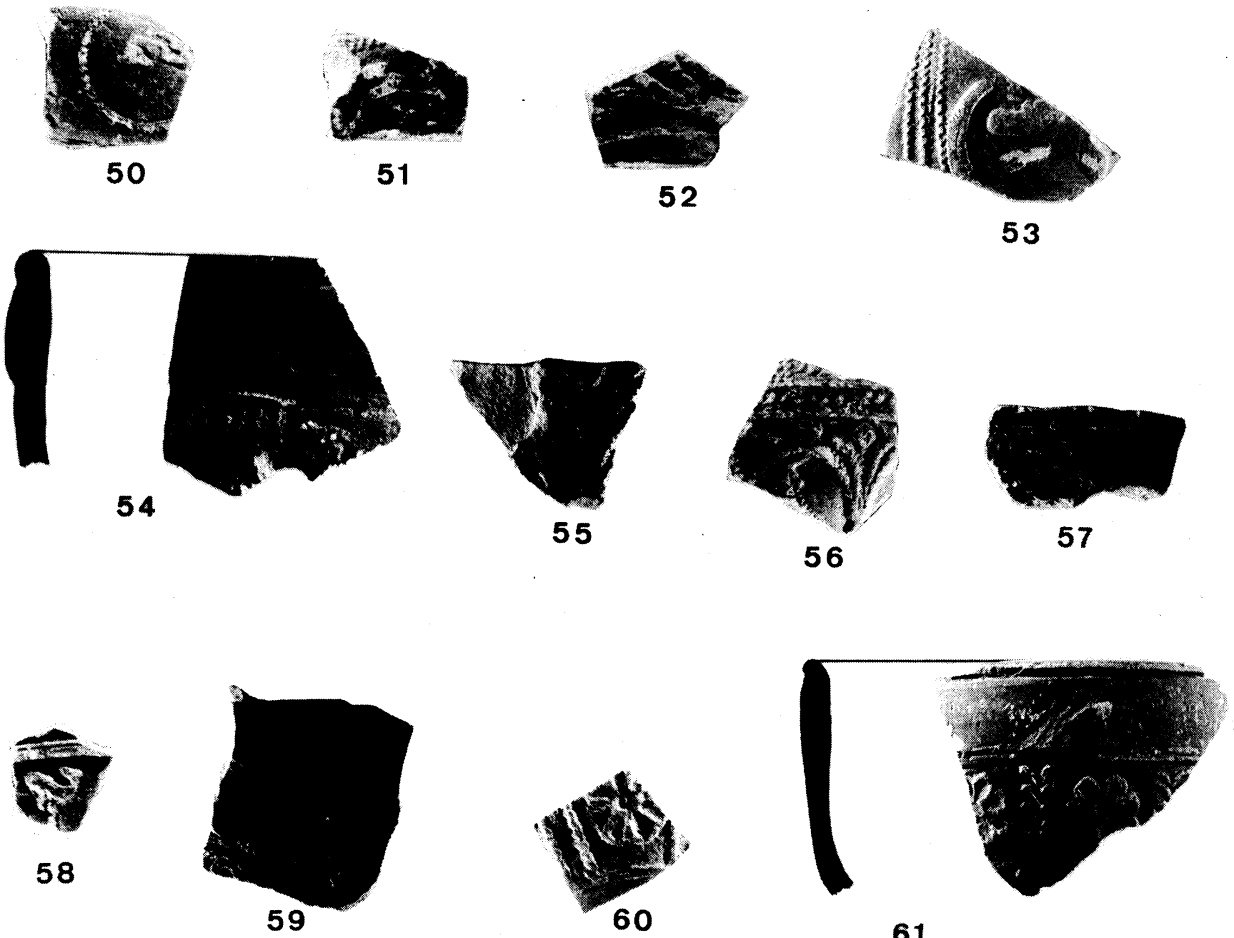

61

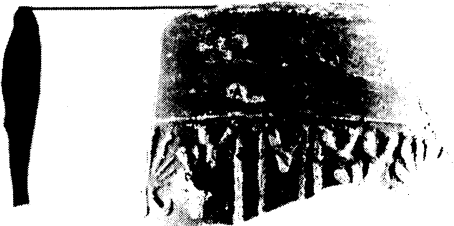

62

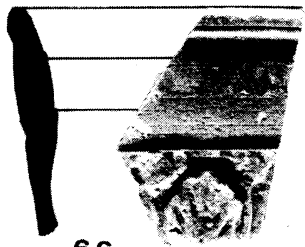

66

0

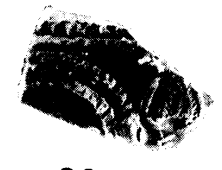

63
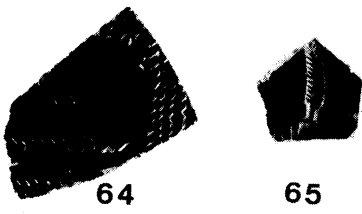
$5 \mathrm{~cm}$.

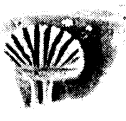

67
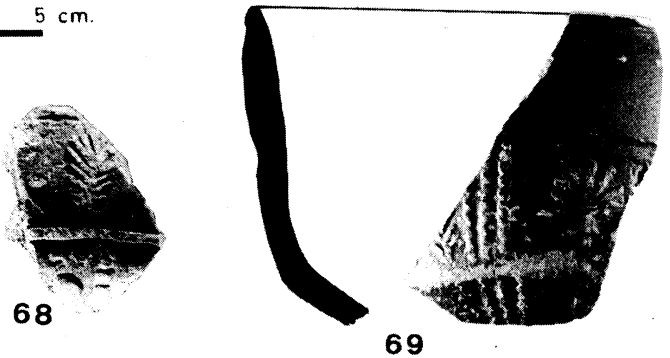

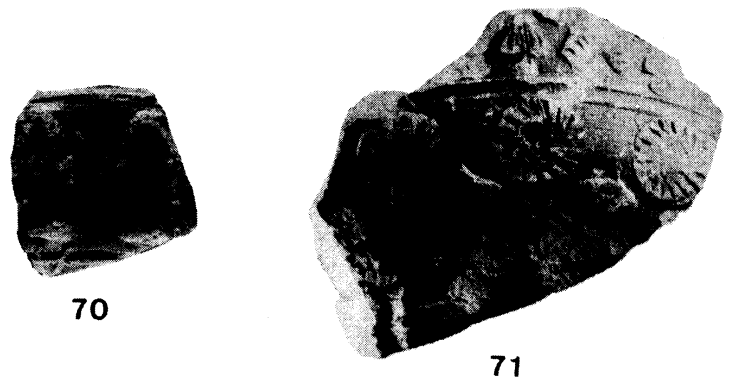

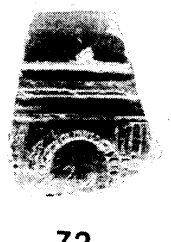

72

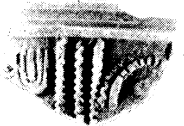

73

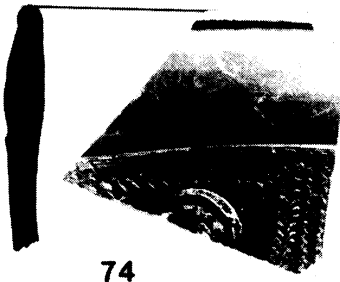

74

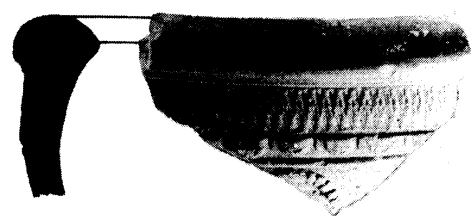

75

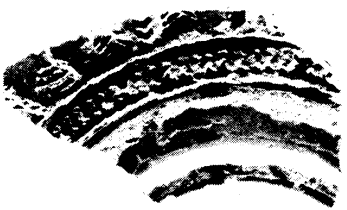

76

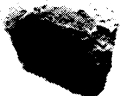

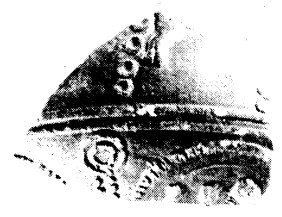

77

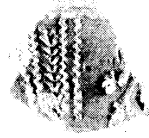

78
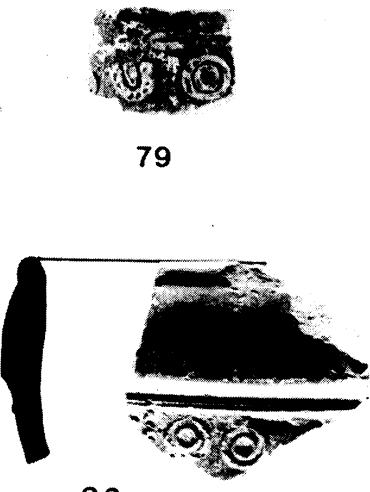

83

82

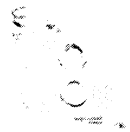

84 $\frac{6}{6}$

81

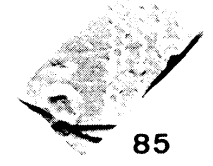

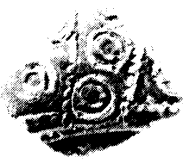

80

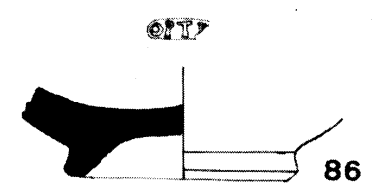

